\title{
Three Types of Ion Channels in the Cell Membrane of Mouse Fibroblasts
}

\section{KOSELSKI ${ }^{1}$, A. OLSZEWSKA ${ }^{2}$, A. HORDYJEWSKA ${ }^{3}$, T. MALECKA-MASSALSKA ${ }^{2}$, K. TREBACZ ${ }^{1}$}

${ }^{1}$ Department of Biophysics, Institute of Biology and Biochemistry, Maria Curie-Skłodowska University, Lublin, Poland, ${ }^{2}$ Department of Human Physiology, Medical University of Lublin, Lublin, Poland, ${ }^{3}$ Department of Medical Chemistry, Medical University of Lublin, Lublin, Poland

Received April 1, 2016

Accepted July 15, 2016

On-line October 26, 2016

\section{Summary}

Patch clamp recordings carried out in the inside-out configuration revealed activity of three kinds of channels: nonselective cation channels, small-conductance $\mathrm{K}^{+}$channels, and large-conductance anion channels. The nonselective cation channels did not distinguish between $\mathrm{Na}^{+}$and $\mathrm{K}^{+}$. The unitary conductance of these channels reached $28 \mathrm{pS}$ in a symmetrical concentration of $200 \mathrm{mM} \mathrm{NaCl}$. A lower value of this parameter was recorded for the small-conductance $\mathrm{K}^{+}$channels and in a 50 -fold gradient of $\mathrm{K}^{+}(200 \mathrm{mM} / 4 \mathrm{mM})$ it reached $8 \mathrm{pS}$. The high selectivity of these channels to potassium was confirmed by the reversal potential $(-97 \mathrm{mV})$, whose value was close to the equilibrium potential for potassium $(-100 \mathrm{mV})$. One of the features of the largeconductance anion channels was high conductance amounting to $493 \mathrm{pS}$ in a symmetrical concentration of $200 \mathrm{mM} \mathrm{NaCl}$. The channels exhibited three subconductance levels. Moreover, an increase in the open probability of the channels at voltages close to zero was observed. The anion selectivity of the channels was low, because the channels were permeable to both $\mathrm{Cl}^{-}$and gluconate - a large anion. Research on the calcium dependence revealed that internal calcium activates nonselective cation channels and small-conductance $\mathrm{K}^{+}$channels, but not largeconductance anion channels.

\section{Key words}

Patch-clamp • Mouse fibroblast • Cell membrane • Cation channels $\bullet \mathrm{K}^{+}$channels $\bullet$ Anion channels

\section{Corresponding author}

M. Koselski, Department of Biophysics, Institute of Biology and Biochemistry, Maria Curie-Skłodowska University, Akademicka 19, 20-033 Lublin, Poland. E-mail: mateusz.koselski@poczta.umcs.lublin.pl

\section{Introduction}

Fibroblasts are the most common type of cells found in connective tissue. They are defined as cells that synthesize and secrete collagen proteins and they are also believed to be an essential source of many other extracellular matrix components (Theerakittayakorn and Bunprasert 2011). Animal or human fibroblasts grow well in cultures and are readily available for experiments; therefore, they have been widely used for investigation of many physiological and biochemical responses. Learning more about their general physiology and ion channel activity in particular is very important (Estacion 1991).

Different types of cation- and anion-selective channels were characterized in mouse fibroblasts using patch-clamp techniques. Voltage-dependent calcium currents were detected in mouse Swiss 3T3 fibroblasts (Peres et al. 1988a, Peres et al. 1988b). These rapidly activating and fully inactivating inward currents were evoked by depolarization from negative voltages and were similar to low-voltage T-type calcium channels activated by small depolarization of the cell membrane potential (Perez-Reyes 2003). Weak permeability of recorded channels to other than calcium divalent cations 
was confirmed by reduction of the currents by $\mathrm{Cd}^{2+}$ (Peres et al. 1988a), and slight reduction of the currents recorded after replacement of external $\mathrm{Ca}^{2+}$ with $\mathrm{Ba}^{2+}$ (Peres et al. 1988b). On the other hand, after elimination of all divalent cations from the external solution, permeability to monovalent cations was observed. A lack of sensitivity to calcium channel blockers like nitrendipine and verapamil was also characteristic for the channels. In the study of Peres and coworkers, an absence of calcium-activated $\mathrm{K}^{+}$channels was reported (Peres et al. 1988a), but such channels were recorded in the mouse fibroblastic line LMTK-, a thymine-kinase-deficient strain of L cells (Hosoi and Slaymann 1985). In turn, cell-attached and inside-out patch recording carried out by Frace and Gargus indicated that the predominant channel of LMTK- was a nonselective calcium- and voltage independent cation channel, permeable equally to $\mathrm{Na}^{+}, \mathrm{K}^{+}$, and $\mathrm{Cs}^{+}$and non-permeable to anions or divalent cations (Frace and Gargus 1989). Apart from mouse LMTK-cells, $\mathrm{Ca}^{2+}$ dependent $\mathrm{K}^{+}$currents were recorded also in NIH3T3 mouse fibroblasts (Repp et al. 1998). The channels were activated by lysophosphatidic acid and showed voltage-independence and sensitivity to the $\mathrm{K}^{+}$channels blockers (charybdotoxin, margatoxin, and iberiotoxin). The whole cell patch-clamp recordings carried out in mouse LMTK-fibroblasts indicated existence of volume-sensitive $\mathrm{Cl}^{-}$currents whose activation is delayed by high intracellular chloride (Doroshenko 1999). Moreover, $\mathrm{Cl}^{-}$conductance of these channels is affected by protein tyrosine phosphatase inhibitors (Thoroed et al. 1999). Mouse skin fibroblasts 3T3-L1 were also used for patch-clamp investigations by Goodwin and coworkers. However, as reported, there were difficulties in obtaining results, since poor seals in both cell-attached and excised inside-out configurations and a low success rate in finding channels $(<10 \%)$ were observed. The channels, rarely recorded in the cell-attached configuration, were not voltage-dependent and probably $\mathrm{K}^{+}$impermeable (Goodwin et al. 1998).

Ion channels play an important physiological role. Many functions and possible roles of some channels are discussed. A big number of ion channelopaties, especially potassium, calcium, and sodium channel diseases, affect the neuromuscular system and cause diseases such as epilepsy, myotonia, or cardiac arrhythmias (Fiske et al. 2006). Defects in ion channels may cause either a gain or a loss of channel function. Changes in the ion channel composition have been observed in fibroblasts from patients with Alzheimer's disease (AD). Etcheberrigaray and coworkers indicated an absence of a 113-pS tetraethylammonium (TEA)-sensitive $\mathrm{K}^{+}$channel in $\mathrm{AD}$ fibroblasts, while they were present in control cells (Etcheberrigaray et al. 1993).

This paper describes ion channels found in the mouse L929 fibroblastic cell line, which is widely used in many experimental aspects. Patch-clamp recordings carried out in the inside-out configuration allowed characterization of three different types of channels, which are important for transport of monovalent cations and anions through the cell membrane.

\section{Materials and Methods}

\section{Cell culture and culture media}

The experiment was conducted on a reference cell line L929 (cell line origin - mouse C3H/An connective tissue). The L929 cell line was obtained from ATCC (specification - NCTC clone 929 [L cell, L-929, derivative of Strain L] (ATCC $\AA$ CCL-1 ${ }^{\mathrm{TM}}$ ), http://www.lgcstandards-atcc.org/products/all/CCL1.aspx?geo_country=pl). Cell cultures were grown at $37{ }^{\circ} \mathrm{C}$ in a humidified atmosphere comprising $5 \% \mathrm{CO}_{2}$ in the air. L929 cultures were maintained at density of $2-4 \times 10^{4} \mathrm{cell} / \mathrm{ml}$ in exponential growth serum free conditions containing Modified Eagle Medium (MEM, Pan-Biotech, P04-08500; http://www.pan-biotech.de/ en/media-en/cell-culture-media/mem-overview/memwith-earle-s-salts) supplemented with $5 \%$ fetal bovine serum (Pan-Biotech, P30-1985, http://www.panbiotech.de/en/sera/treated-sera), $100 \mathrm{U} / \mathrm{ml}$ of penicillin, $100 \mu \mathrm{g} / \mathrm{ml}$ of streptomycin, $0.25 \mu \mathrm{g} / \mathrm{ml}$ of amphotericin B (Pan-Biotech, P06-07300; http://www.panbiotech.de/en/reagents/antibiotics-and-antifungal-drugs), and routinely passaged every second day using $0.25 \%$ trypsin (Pan-Biotech, P10-027500; http://www.panbiotech.de/en/reagents/enzymes-for-cell-dissociation/ trypsin-and-others). Cell viability was assessed by the ability to exclude trypan blue dye (Sigma-Aldrich, Germany, T6146). Cells for patch-clamp experiments were transferred to plastic $60-\mathrm{mm}$ tissue culture dishes and grown in the same conditions for up 2 days.

\section{Solutions used in the patch-clamp recordings}

Patch-clamp recordings were made in the insideout configuration in solutions initially containing symmetrical (in the pipette and in the bath) concentrations of $200 \mathrm{mM} \mathrm{NaCl}, 4 \mathrm{mM} \mathrm{KCl}, 2 \mathrm{mM}$ $\mathrm{CaCl}_{2}, 2 \mathrm{mM} \mathrm{MgCl}_{2}$, pH 7.3 buffered with $10 \mathrm{mM}$ 
HEPES/NaOH (abbreviation of these solutions used in figure legends and text $-200 \mathrm{Na}_{\text {pipette }}^{+} / 200 \mathrm{Na}^{+}{ }_{\text {bath }}$ ). The selectivity of the channels was examined in a $\mathrm{NaCl}$ gradient after tenfold reduction of $\mathrm{NaCl}$ in the bath by application of $20 \mathrm{mM} \mathrm{NaCl}, 4 \mathrm{mM} \mathrm{KCl}, 2 \mathrm{mM} \mathrm{CaCl}_{2}$, $2 \mathrm{mM} \quad \mathrm{MgCl}_{2}, \quad \mathrm{pH} \quad 7.3$ buffered with $10 \mathrm{mM}$ HEPES/NaOH (abbreviation - $200 \mathrm{Na}_{\text {pipette }}^{+} / 20 \mathrm{Na}^{+}$bath). Permeability of cation-permeable channels to potassium was studied by replacement of $\mathrm{NaCl}$ in the bath with $\mathrm{KCl}$ - of $200 \mathrm{mM} \mathrm{KCl}, 4 \mathrm{mM} \mathrm{NaCl}, 2 \mathrm{mM} \mathrm{CaCl}_{2}, 2 \mathrm{mM}$ $\mathrm{MgCl}_{2}$, pH 7.3 buffered with $10 \mathrm{mM}$ HEPES/KOH (abbreviation $-200 \mathrm{Na}_{\text {pipette }}^{+} / 200 \mathrm{~K}^{+}{ }_{\text {bath }}$ ). Permeability of anion-permeable channels to gluconate was studied in $20 \mathrm{mM} \mathrm{NaCl}, 4 \mathrm{mM} \mathrm{KCl}, 2 \mathrm{mM} \mathrm{CaCl} 2,2 \mathrm{mM} \mathrm{MgCl}_{2}$, pH 7.3 buffered with $10 \mathrm{mM}$ HEPES/NaOH in the bath and $200 \mathrm{mM}$ Na-gluconate, $4 \mathrm{mM} \mathrm{KCl}, 2 \mathrm{mM} \mathrm{CaCl}$, $2 \mathrm{mM} \quad \mathrm{MgCl}_{2}$, pH 7.3 buffered with $10 \mathrm{mM}$ $\mathrm{HEPES} / \mathrm{NaOH}$ in the pipette (abbreviation $200 \mathrm{Glu}_{\text {pipete }}^{-} / 32 \mathrm{Cl}_{\text {bath }}^{-}$). Calcium dependence of the channels was tested during inside-out recordings by application of the solution containing $2 \mathrm{mM} \mathrm{Ca}^{2+}$ (200 mM KCl, $4 \mathrm{mM} \mathrm{KCl,} 2 \mathrm{mM} \mathrm{CaCl}, 2 \mathrm{mM} \mathrm{MgCl}$, $\mathrm{pH} 7.3$ buffered with $10 \mathrm{mM}$ HEPES/KOH) by a micropipette placed close to the cytoplasmic side of the cell membrane. Calcium was injected using a CellTram vario pump (Eppendorf, Hamburg). Before calcium application, the recordings were carried out in $200 \mathrm{mM}$ $\mathrm{NaCl}, 4 \mathrm{mM} \mathrm{KCl}, 2 \mathrm{mM} \mathrm{CaCl}, 2 \mathrm{mM} \mathrm{MgCl}_{2}, \mathrm{pH} 7.3$

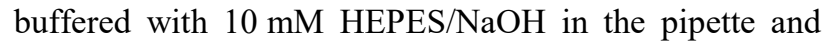
$200 \mathrm{mM} \mathrm{KCl}, 4 \mathrm{mM} \mathrm{NaCl}, 2 \mathrm{mM}$ EGTA, $2 \mathrm{mM} \mathrm{MgCl}_{2}$, $\mathrm{pH} 7.3$ buffered with $10 \mathrm{mM} \mathrm{HEPES} / \mathrm{KOH}$ in the bath (abbreviation - $200 \mathrm{Na}^{+}, 2 \mathrm{Ca}^{2+}$ pipette $/ 200 \mathrm{~K}^{+}, 2 \mathrm{EGTA}_{\text {bath }}$ ). The osmolarity of solutions with a reduced ionic concentration was compensated by adding sorbitol. Adjusting of the osmolarity was measured with a cryoscopic osmometer (Osmomat 030, Gonotec).

\section{Patch-clamp measurements}

The patch pipettes and micropipettes used for injection of $\mathrm{Ca}^{2+}$ were prepared from borosilicate glass capillary tubes with an outer diameter of $1.5 \mathrm{~mm}$ (Kwik-Fil, TW150-4, World Precision Instruments), pulled by a universal puller (DMZ). The patch pipette tip had an inside diameter of approx. $2 \mu \mathrm{m}$. An $\mathrm{Ag}-\mathrm{AgCl}$ reference electrode filled with $100 \mathrm{mM} \mathrm{KCl}$ was connected with the bath solution via a ceramic porous bridge. The recordings were made by a patch-clamp amplifier EPC-10 (Heka Electronik) coupled with the Patchmaster software (Heka Elektronik). The signals were recorded with a frequency of $10 \mathrm{kHz}$ and filtered at $2 \mathrm{kHz}$. The recordings, which lasted $10 \mathrm{~s}$ or more (Fig. 5), were drawn by taking into account every tenth measuring point. Elaboration of the current/voltage characteristics (I/V) and column diagrams showing dependence of the open probability on the voltage applied was made in SigmaPlot 9.0 (Systat Software Inc.). The slope of the I/V curve allowed calculation of the unitary conductance of the channels. Open probability of the channels was calculated in Fitmaster (Heka Elektronik).

\section{Statistical analysis}

Data presented in the $\mathrm{I} / \mathrm{V}$ curves and $\mathrm{P}_{\mathrm{o}} / \mathrm{V}$ column charts are given as arithmetic mean \pm standard error of the mean (SEM). The number of repeats $(n)$ indicates the number of patches tested. The open probability of a single channel was calculated as the ratio of the open time and the total recording time (the sum of open and close time). In the case of activity of more than one channel in the patch, the open probability was divided by the number of active channels. Statistical significance was evaluated using a $t$-test (for two groups) or ANOVA with Bonferroni post-hoc test (for more than two groups). Data were compiled using SigmaStat (version 3.5). A value of $P$ lower than 0.05 was considered statistically significant.

\section{Results}

\section{Nonselective cation channels}

The predominant type of ion currents recorded in the cell membrane of mouse fibroblasts were those that passed through nonselective cation channels (Fig. 1A). The activity of these channels was recorded in most (58\%, 15 out of 26) of the patches tested in the inside-out configuration in the symmetrical (in the bath and in the pipette) concentration of $200 \mathrm{mM} \mathrm{NaCl}$. In such conditions, the channels were active in negative and positive voltages carrying the ions in both directions of the membrane. Their unitary conductance (established from the slope of the I/V curve) reached $28 \mathrm{pS}$. The value of this parameter was lower in the ten-fold gradient of $\mathrm{NaCl}$ ( $200 \mathrm{mM} \mathrm{NaCl}$ in the pipette and $20 \mathrm{mM} \mathrm{NaCl}$ in the bath) and amounted to $25 \mathrm{pS}$ (Fig. 1B). The conditions used caused decline of the channel activity at positive voltages and an increase in the open probability at negative voltages (Fig. 1D) and indicated that $\mathrm{Na}^{+}$ions flowed through the channels in accordance with their electrochemical gradient. The reversal potential obtained from the $\mathrm{I} / \mathrm{V}$ curve 
(Fig. 1C) shifted toward positive values and reached $24 \mathrm{mV}$ - a value closer to the equilibrium potential of sodium $\left(\mathrm{E}_{\mathrm{Na}}=54 \mathrm{mV}\right)$ than chloride $\left(\mathrm{E}_{\mathrm{Cl}}=-44 \mathrm{mV}\right)$ calculated on the basis of ion activities. The above results indicated $\mathrm{Na}^{+}$over $\mathrm{Cl}^{-}$selectivity of the channels.
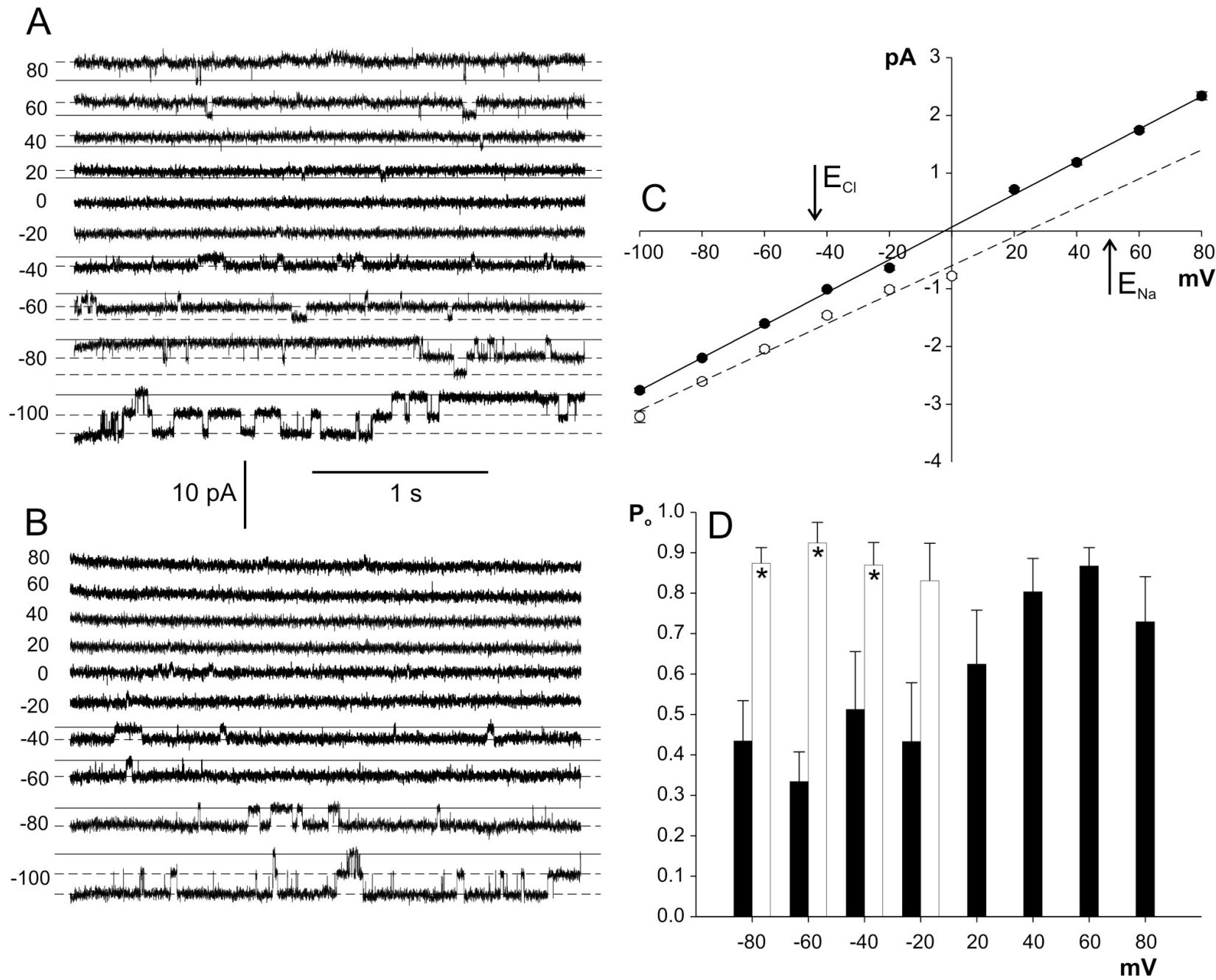

Fig. 1. Activity of nonselective cation channels recorded in the cell membrane from mouse fibroblasts. (A) Inside-out recordings carried out in $200 \mathrm{Na}^{+}{ }_{\text {pipette/ }} / 200 \mathrm{Na}^{+}{ }_{\text {bath. }}$. The solid line indicates the closed state of the channels and the dashed line - open states. The values of holding voltages (in $\mathrm{mV}$ ) are placed on the left side of the traces. (B) Recordings obtained after tenfold reduction of the $\mathrm{Na}^{+}$concentration in the bath $\left(200 \mathrm{Na}^{+}{ }_{\text {pipette }} / 20 \mathrm{Na}^{+}{ }_{\text {bath }}\right)$. (C) I/V curves obtained in the same conditions as in A (solid line, $\left.\mathrm{n}=10\right)$, and B (dashed line, $n=6$ ). The arrows indicate the reversal potential for $\mathrm{Cl}^{-}$and $\mathrm{Na}^{+}$based on the activity of these ions in the solutions as in $\mathrm{B}$. (D) Dependence of the open probability $\left(\mathrm{P}_{0}\right)$ of the channels on the voltage applied. The data were obtained in the same conditions as in $\mathrm{A}$ (black columns, $\mathrm{n}=5$ ) and $\mathrm{B}$ (white columns, $\mathrm{n}=5$ ). The asterisks indicate statistically significant differences $(P<0.05)$. Statistical significance was evaluated using a $t$-test. The values of $P$ obtained at $-80 \mathrm{mV},-60 \mathrm{mV}$, and $-40 \mathrm{mV}$ amounted to $0.003,0.001$, and 0.048 , respectively.

The difference between the reversal potential obtained from the measurements and $\mathrm{E}_{\mathrm{Na}}$, was the reason for a more detailed study of the low cation-selectivity of the channels. In order to compare the selectivity of the channels to $\mathrm{K}^{+}$and $\mathrm{Na}^{+}$, a 50 -fold gradient facilitating outward $\mathrm{K}^{+}$currents and inward $\mathrm{Na}^{+}$currents was applied (Fig. 2A). In such conditions, the reversal potential obtained from the I/V curve (Fig. 2C) amounted to $-1 \mathrm{mV}$, which proved that the channels did not distinguish
$\mathrm{K}^{+}$and $\mathrm{Na}^{+}$ions. In comparison to the experiments carried out in symmetrical concentration $200 \mathrm{Na}^{+}$, the exchange of $200 \mathrm{mM} \mathrm{Na}{ }^{+}$on the cytoplasmic side to $200 \mathrm{mM} \mathrm{K}^{+}$caused an increase in channel conductance from $28 \mathrm{pS}$ (Fig. 1A, C) to $33 \mathrm{pS}$ (Fig. 2A, C).

\section{Small-conductance $K^{+}$channels}

Small-conductance $\mathrm{K}^{+}$channel activity was recorded in identical conditions as in the earlier 
experiments carried out in the 50-fold gradient of $\mathrm{K}^{+}$and $\mathrm{Na}^{+}\left(200 \mathrm{Na}^{+}{ }_{\text {pipette }} / 200 \mathrm{~K}^{+}\right.$bath , Fig. 2B, D). These currents were recorded in $36 \%$ (5 of 14) of the patches. The channel conductance was much lower than the conductance of nonselective cation channels and amounted to $8 \mathrm{pS}$. The high selectivity of the channels to potassium was confirmed by the value of the reversal potential obtained from the I/V curve (Fig. 2D), which amounted to $-97 \mathrm{mV}$ - a value close to the equilibrium potential of potassium $(-100 \mathrm{mV})$.
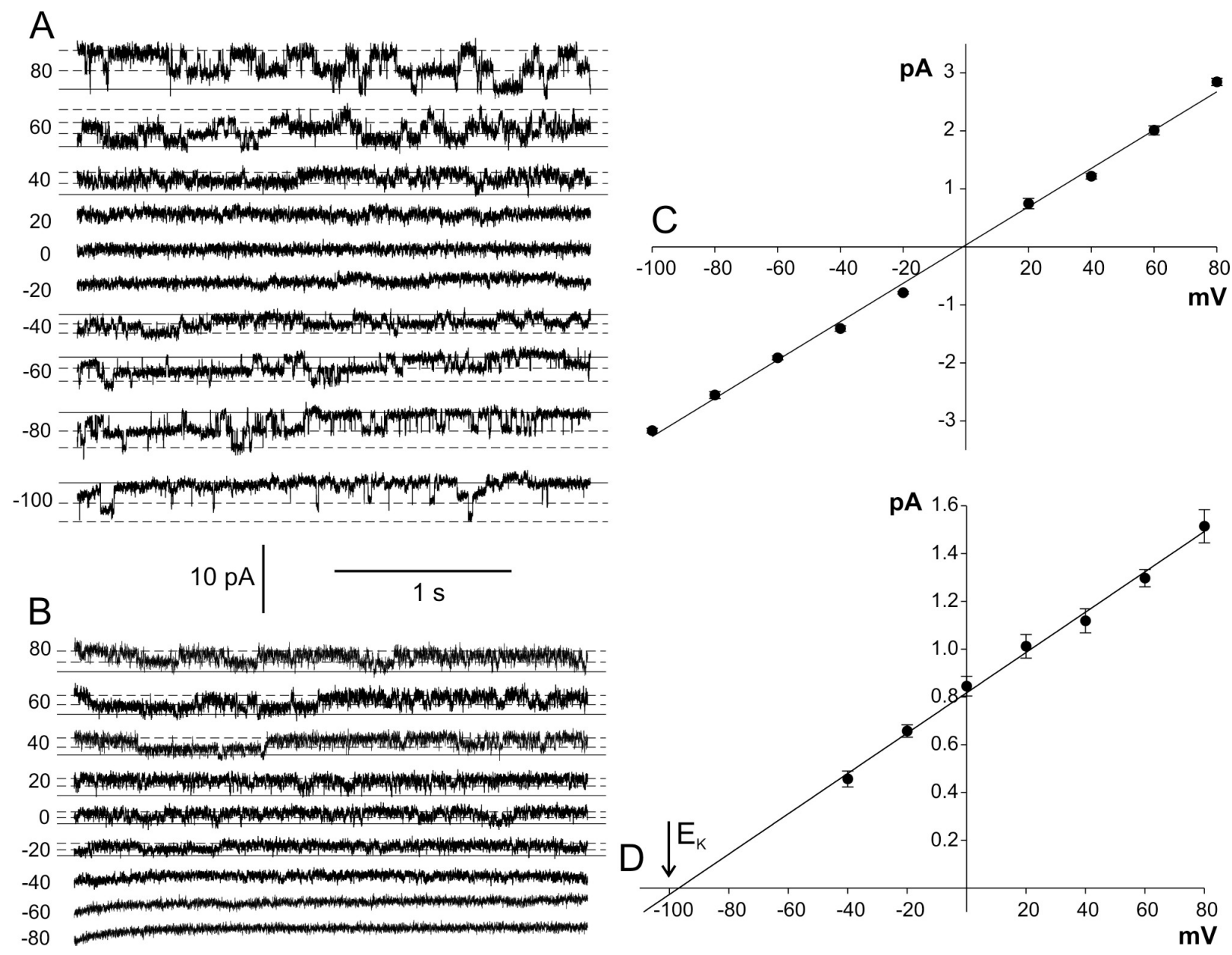

Fig. 2. Permeability of the channels from the cell membrane of mouse fibroblasts to $\mathrm{K}^{+}$. (A) Inside-out recordings carried out in $200 \mathrm{Na}^{+}{ }_{\text {pipette }} / 200 \mathrm{~K}^{+}$bath. (B) Inside-out recordings carried out in the same conditions as in A showing the activity of $\mathrm{K}^{+}$selective channels with small conductance. (C, D) I/V curves characterizing the cation-permeable channels from $A(C, n=5)$ and the $K^{+}$selective channels from $B(D, n=5)$. The arrow indicates the reversal potential for $\mathrm{K}^{+}$calculated from the activity of this ion in the solutions.

\section{Large-conductance anion channels}

Apart from the channels described previously, large-conductance channels were recorded. These channels recorded in the symmetrical concentration of $200 \mathrm{mM}$ $\mathrm{NaCl}$ (Fig. 3A, D) were active in $42 \%$ (11 of 26) of the patches. Interestingly, the channels were not active immediately after excision, but required several minutes of polarization of the patch (by 3-second impulses in the range from $-80 \mathrm{mV}$ to $80 \mathrm{mV}$ with $20 \mathrm{mV}$ steps). A characteristic trait of the channels was their high conductance amounting to $493 \mathrm{pS}$. Tenfold reduction of the concentration of cytoplasmic $\mathrm{NaCl}$ caused reduction of the conductance to $296 \mathrm{pS}$ and also a shift of the reversal potential to $-29 \mathrm{mV}$, indicating $\mathrm{Cl}^{-}$over $\mathrm{Na}^{+}$selectivity of the channels (Fig. 3B, D). The channels were not highly selective for chloride since their activity was not inhibited by the substitution of cytoplasmic $200 \mathrm{mM} \mathrm{Cl}^{-}$by $200 \mathrm{mM}$ gluconate - an anion impermeable to chloride channels. The presence of cytoplasmic gluconate instead of $\mathrm{Cl}^{-}$ caused a decrease in conductance from $296 \mathrm{pS}$ to $82 \mathrm{pS}$, which indicates that the channels are less permeable to gluconate than to chloride (Fig. 3C, D). The relative permeability ratio of gluconate with respect to chloride $\left(P_{g l u} / P_{C l}\right)$ was low and reached 0.1 . 


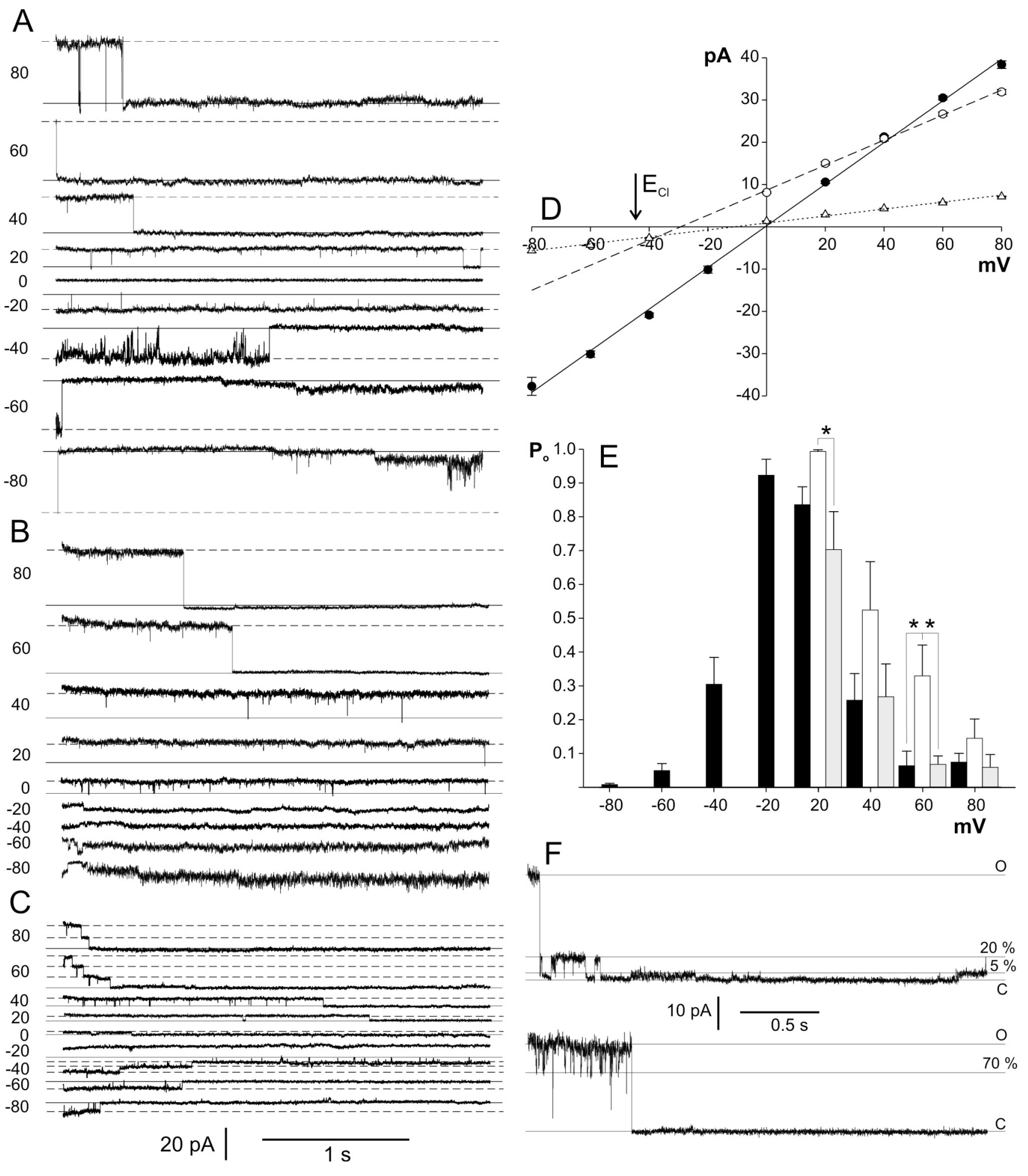

Fig. 3. Activity of large conductance anion channels recorded in the cell membrane from mouse fibroblasts. (A) Inside-out recordings carried out in $200 \mathrm{Na}^{+}$pipette/200 Na${ }_{\text {bath. }}$ (B) Recordings obtained after tenfold reduction of the $\mathrm{Na}^{+}$concentration in the bath $\left(200 \mathrm{Na}^{+}{ }_{\text {pipette }} / 20 \mathrm{Na}^{+}{ }_{\text {bath }}\right)$. (C) Recordings showing a decrease in single channel conductance in $200 \mathrm{Glu}_{\text {pipette }}^{-} / 32 \mathrm{Cl}_{\text {bath. }}^{-}$(D) I/V curves obtained in the same conditions as in $A$ (solid line, $n=6$ ), B (dashed line, $n=6$ ), and $C$ (dotted line, $n=6$ ). The arrow indicates the reversal potential for $\mathrm{Cl}^{-}$calculated from the activity of these ions in the solutions as in $\mathrm{B}$. (E) Dependence of the open probability $\left(\mathrm{P}_{\mathrm{o}}\right)$ of the channels on the voltage applied. The data were obtained in the same conditions as in A (black columns, $n=5$ ), $B$ (white columns, $\mathrm{n}=5$ ), and $\mathrm{C}$ (grey columns, $\mathrm{n}=5$ ). The asterisks indicate statistically significant differences $(P<0.05)$. Statistical significance was evaluated using a one-way ANOVA with Bonferroni pairwise multiple comparison. The values of $P$ obtained at $20 \mathrm{mV}$ amounted to 0.043. The values of $P$ obtained at $60 \mathrm{mV}$ amounted to 0.026 (left asterisk) and 0.028 (right asterisk). (F) Subconductance levels of large-conductance anion channels. The inside-out recordings obtained at $80 \mathrm{mV}$ (upper panel) and at $60 \mathrm{mV}$ (lower panel) in $200 \mathrm{Na}^{+}{ }_{\text {pipette }} / 20 \mathrm{Na}^{+}{ }_{\text {bath. }} \mathrm{C}$ and $\mathrm{O}$ indicate closed state and open state, respectively. The subconductance levels (5\%, $20 \%$ and $\left.70 \%\right)$ are indicated. 
A characteristic feature of the channels was their activation in the narrow range of voltages, since the open probability of the channels was the highest close to $0 \mathrm{mV}$ (Fig. 3E). The values of this parameter recorded at positive voltages were higher in conditions promoting outward currents carried by $\mathrm{Cl}^{-}$flowing from the extracellular to the cytoplasmic side of the cell membrane than those obtained in the symmetrical $\mathrm{Cl}^{-}$concentration. For instance, at $60 \mathrm{mV}$, the open probability increased from $0.064 \pm 0.043$ to $0.33 \pm 0.091 \quad(n=5)$. The open probability of the channels recorded at positive voltages was also reduced after replacement of extracellular $\mathrm{Cl}^{-}$ with gluconate. The value of this parameter recorded at $60 \mathrm{mV}$ was reduced from $0.33 \pm 0.091$ to $0.068 \pm 0.025$ $(n=5)$.

During the recordings carried out in a $\mathrm{NaCl}$ gradient that reduced cation-permeable channel activity at positive voltages (Fig. 1B, 3B) apart from the main open level, three subconductance levels of the anion-permeable channels were observed (Fig. 3F). The channel subconductance levels in the presented recordings at positive voltages were $5 \%(20 \mathrm{pS}), 20 \%(75 \mathrm{pS})$, and $70 \%(297 \mathrm{pS})$.

The range of voltages that activate the channels was studied by application of two kinds of ramp voltages: from $-80 \mathrm{mV}$ to $+80 \mathrm{mV}$ and from $+80 \mathrm{mV}$ to $-80 \mathrm{mV}$. The measurements carried out in the symmetrical $\mathrm{Cl}^{-}$concentration proved that the channels were activated in a narrow range of voltages (Fig. 4A, B). Even after application of the $\mathrm{Cl}^{-}$gradient promoting outward currents carried by chloride (Fig. 4C, D), the channels closed at voltages close to $60-70 \mathrm{mV}$. The ramp protocol used in the measurements of the channel activity after application of the $\mathrm{Cl}^{-}$gradient allowed estimation of the reversal potential, which was close to $\mathrm{E}_{\mathrm{Cl}}$ (Fig. 4C, D).

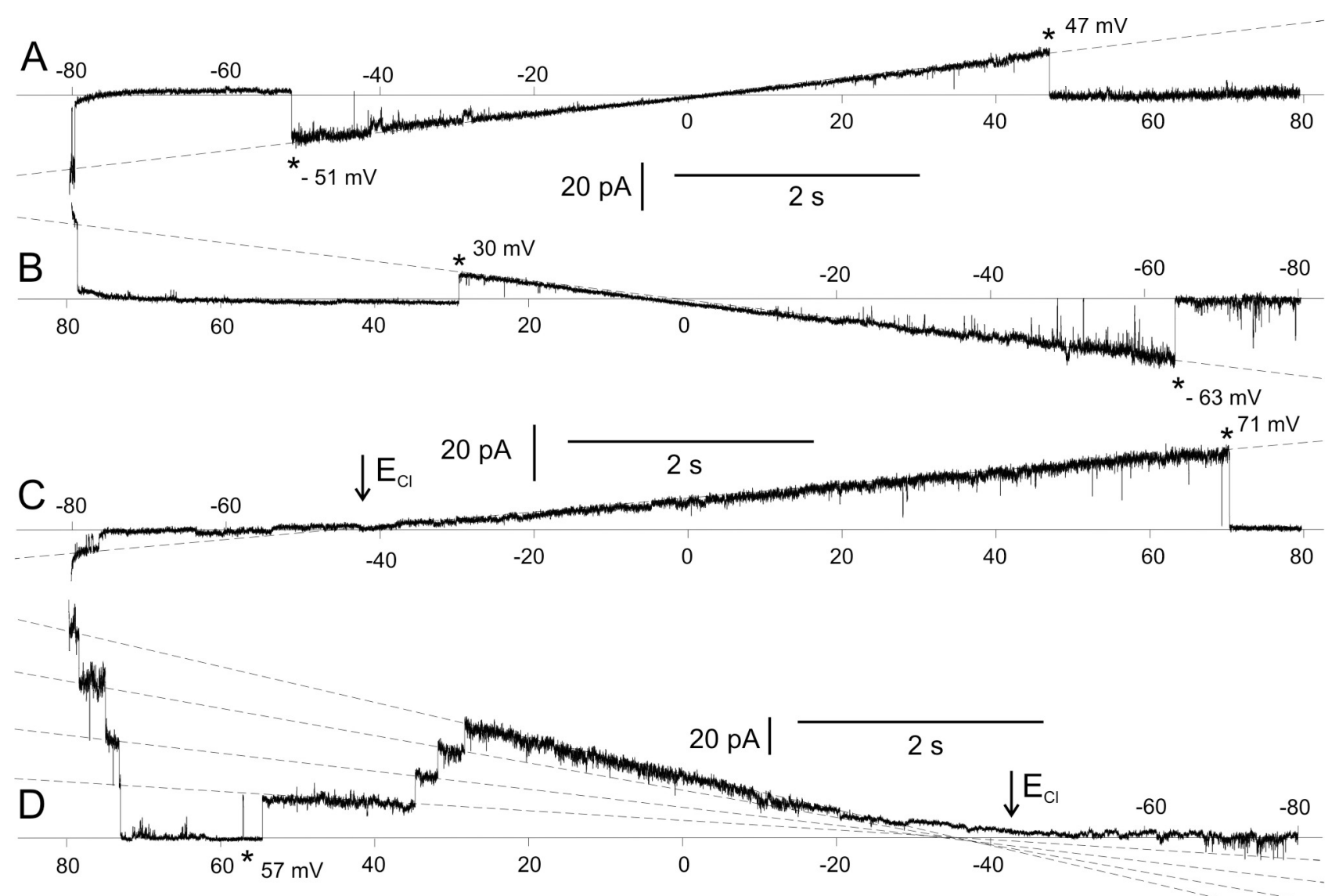

Fig. 4. Activity of large-conductance anion channels recorded during ramp voltages. (A, B) Inside-out recordings obtained in $200 \mathrm{Na}^{+}{ }_{\text {pipettel }} / 200 \mathrm{Na}^{+}{ }_{\text {bath. }}$ (C) D) Recordings obtained after tenfold reduction of the $\mathrm{Na}^{+}$concentration in the bath $\left(200 \mathrm{Na}^{+}{ }_{\text {pipette }} / 20 \mathrm{Na}^{+}{ }_{\text {bath }}\right)$. The arrows indicate the reversal potential for $\mathrm{Cl}^{-}$calculated from the activity of this ion in the solutions. The values of the voltage applied (in $\mathrm{mV}$ ) are placed in the abscissa axis. The dashed lines indicate the open states of the channels and allow determining the reversal potential. The asterisks indicate the value of the voltage that activated the channels. 


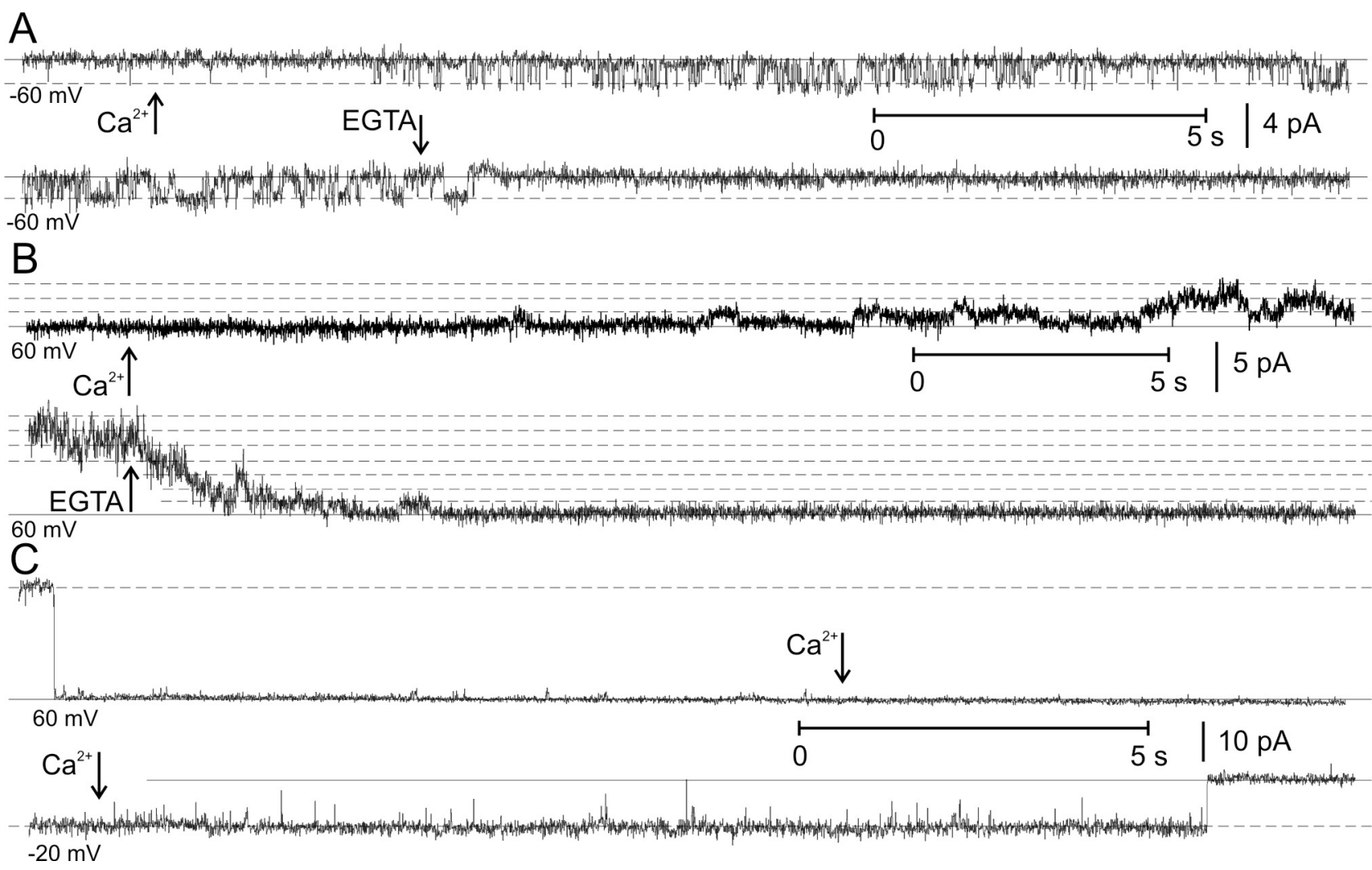

Fig. 5. Calcium dependence of different types of ion currents recorded in mouse fibroblasts. The inside-out measurements were carried out in the absence of $\mathrm{Ca}^{2+}$ in the bath $\left(200 \mathrm{Na}^{+}, 2 \mathrm{Ca}^{2+}{ }_{\text {pipette }} / 200 \mathrm{~K}^{+}, 2 \mathrm{EGTA}_{\text {bath }}\right)$. The calcium dependence was studied for nonselective cation channels (A), small-conductance $\mathrm{K}^{+}$-selective channels (B), and large-conductance anion channels (C). The Ca ${ }^{2+}$-containing solution $(200 \mathrm{mM} \mathrm{KCl}, 4 \mathrm{mM} \mathrm{NaCl}, 2 \mathrm{mM} \mathrm{CaCl}, 2 \mathrm{mM} \mathrm{MgCl}$, pH 7.3 buffered with $10 \mathrm{mM} \mathrm{HEPES} / \mathrm{NaOH}$ ) was placed inside a micropipette connected to the pump. During the inside-out recordings, the micropipette was brought close to the patch pipette and the solution was injected. The moment of $\mathrm{Ca}^{2+}$ injection is indicated by an arrow. The arrow signed as EGTA indicates the moment of withdrawal of the patch pipette from the stream of the injected $\mathrm{Ca}^{2+}$-containing solution. The values of holding voltages are placed at the bottom of the recordings.

\section{Calcium dependence of the channels}

Since internal $\mathrm{Ca}^{2+}$ activates some channels found in fibroblasts, e.g. non-selective channels from human skin fibroblasts (Galietta et al. 1989), or potassium channels from rat cardiac fibroblasts (Choi et al. 2008), we decided to study the calcium dependence of all channels recorded in the mouse fibroblasts cell line L929. Calcium dependence was studied in $\mathrm{a} \mathrm{Ca}^{2+}$-free bath medium by injection of $2 \mathrm{mM} \mathrm{Ca}^{2+}$ to the internal site of the membrane during inside-out recordings.

The presence of internal calcium was necessary to maintain the activity of nonselective cation channels. These channels were not recorded in the $\mathrm{Ca}^{2+}$-free bath medium but injection of $\mathrm{Ca}^{2+}$ rapidly (within a few seconds) activated the channels (Fig. 5A, upper panel). The channels were also rapidly inactivated after removal of the membrane from the stream of the $\mathrm{Ca}^{2+}$-containing solution (Fig. 5A, lower panel). A relatively long time was necessary for activation of small-conductance $\mathrm{K}^{+}$channels (Fig. 5B, upper panel). These channels were also recorded in a $\mathrm{Ca}^{2+}$-free bath medium within tens of seconds after excision or several or more seconds after chelation of $\mathrm{Ca}^{2+}$ by EGTA (Fig. 5B, lower panel). Such results indicate that the $\mathrm{Ca}^{2+}$ binding/unbinding process proceeds more slowly in small-conductance potassium channels than in nonselective cation channels. No calcium dependence was observed in the largeconductance anion channels (Fig. 5C). Injection of $\mathrm{Ca}^{2+}$ neither opened the channels at voltages which usually caused their inactivation (Fig. 5C, upper panel) nor changed the channels' activity recorded at voltages close to zero (Fig. 5C, lower panel). The results indicate that voltage but not calcium is the main factor that regulates the activity of large-conductance anion channels.

\section{Discussion}

In this study carried out on the membrane of the mouse fibroblast cell line L929, three different ion channel activities were observed. Most often, the activity 
of nonselective cation channels was recorded. The channel selectivity did not allow distinguishing between sodium and potassium. Similar channels nonselective for cations activated by a platelet-derived growth factor were previously described in mouse fibroblasts in the LMTK cell line (Frace and Gargus 1989). Apart from the equal selectivity for basic monovalent cations, a common feature of the channels from the $\mathrm{LMTK}^{-}$and L929 cell lines was their conductance amounting to $28 \mathrm{pS}$ for both channels. Another parameter that can be taken into account in the comparison of both channels is their voltage dependence. Channels from the L929 cell line recorded in symmetrical concentration $200 \mathrm{mM} \mathrm{NaCl}$ opened with a high open probability at positive voltages (Fig. 1D), while the channels from the LMTK ${ }^{-}$cell line were voltage independent. On the other hand, the voltage dependence of the channels determined in this study is similar to sodium and potassium nonselective channels from human fibroblasts, which opened with a higher probability at positive voltages and passed the cations with the conductance of 14 to $25 \mathrm{pS}$ (Galietta et al. 1989). Moreover, in contrast to the channels from the LMTK cell line, the channels from the human fibroblasts and L929 cell line were activated by cytoplasmic calcium. It seems that the voltage and calcium dependence of nonselective cation channels is not a common feature of channels from different organisms or even from different cell lines.

The second type of the channels recorded in our study was the small-conductance $\mathrm{K}^{+}$channel characterised by low conductance reaching $8 \mathrm{pS}$ (Fig. 2) and $\mathrm{Ca}^{2+}$ dependence (Fig. 6B). According to the present knowledge, there are no similar channels in mammalian fibroblasts and it is hard to classify the channels to other known types of channels. The main features of the smallconductance $\mathrm{K}^{+}$channels analysed in this study are similar to small conductance $\mathrm{Ca}^{2+}$-activated $\mathrm{K}^{+}$channels (SK channels) encoded by at least three genes: $S K 1, S K 2$, and SK3 (Kohler et al. 1996). Apart from small unitary conductance (2-20 pS), $\mathrm{Ca}^{2+}$ sensitivity (submicromolar concentrations), weak voltage dependence, and susceptibility to blockade by d-tubocurarine and apamin are characteristic for SK channels (Kohler et al. 1996, Xia et al. 1998, Hirschberg et al. 1999, Soh and Park 2002). All the three subtypes of SK are present in mouse atrial and ventricular myocytes (Tuleja et al. 2005), where heteromeric SK2-SK3 channels contribute to action potential repolarization (Hancock et al. 2015). In turn, in mouse urinary bladder, the $S K 2$ gene is expressed and is essential for regulation of the smooth muscle contractility by SK channels (Thorneloe et al. 2008).

The third type of the channels recorded in our study was the large-conductance anion channel (Fig. 3). Similar channels were recorded and characterized earlier in different cell types, including human fibroblasts (Nobile and Galietta 1988). Apart from the large conductance of the channels from mouse (493 pS in the symmetrical concentration of $200 \mathrm{mM} \mathrm{NaCl}$ ) and human (300 pS in symmetrical $135 \mathrm{mM} \mathrm{NaCl}$ ), a common feature of the channels was their similar voltage dependence, since the channels from human fibroblasts were usually open at voltages between -20 to $+20 \mathrm{mV}$ and more positive or negative voltages closed the channels. A bell-shaped curve of the open probability with the highest value of this parameter at the voltage close to the reversal potential/zero $\mathrm{mV}$ was found in large-conductance anion channels from other types of cultured cells, for instance in human T-lymphocytes (Pahapill and Schlichter 1992), rabbit colonic smooth muscle (Sun et al. 1992), or pigmented ciliary epithelial (PCE) cells (Mitchell et al. 1997). Moreover, the activity of a large-conductance channel from PCE was also recorded several minutes after polarization, similar to the one recorded in this study. The next feature of largeconductance channels, similar to the channels recorded in this study, is their low selectivity and nearly equal permeability to gluconate and other anions like $\mathrm{I}, \mathrm{Br}$, $\mathrm{NO}_{3}, \mathrm{~F}, \mathrm{SCN}$, glucuronate, $\mathrm{HCO}_{3}$, aspartate and acetate (Stumpff et al. 2009, Bosma 1989, Dixon et al. 1993). The relative permeability ratio of gluconate in respect to $\mathrm{Cl}^{-}$obtained by Stumpff and coworkers from ruminal epithelial cells from sheep $\left(P_{g l u} / P_{C l}=0.16\right.$; Stumpff et al. 2009), was close to the value of this parameter obtained in our study $\left(P_{g l u} / P_{C l}=0.1\right)$. Besides gluconate, low permeability ratios of aspartate and fluoride in respect to chloride were recorded in channels from a mouse B lymphocyte cell line $\left(P_{\text {aspartate }} / P_{C l}=0.62\right.$; Bosma 1989), and muscle vesicles prepared from Ascaris suum $\left(P_{F} / P_{C l}=0.52\right.$; Dixon et al. 1993). Large-conductance channels from a mouse B lymphocyte and the channels characterized in this study possess another similar feature - the existence of three subconductance levels. Among the three subconductance levels recorded in mouse B lymphocyte reaching $30 \%, 55 \%$, and $75 \%$ of the total conductance, one was close to that recorded in our study (70\%, Fig. 3F). Subconductance levels were also recorded in the channels from other kinds of cells like the Golgi complex from rat liver (Thompson et al. 2002), 
human L-lymphocytes (Pahapill and Schlichter 1992), rat cardiac myocytes (Coulombe and Coraboeuf 1992), rat cortical astrocytes (Jalonen 1993), and rabbit colonic smooth muscle (Sun et al. 1992).

In conclusion, this study has proved the existence of three different ion channel types in mouse fibroblasts, which exhibit common features with known channels of other cells/cell lines. Three channel types with known physiological functions are the candidates for being active in mouse fibroblasts: non-selective for cations, small-conductance $\mathrm{Ca}^{2+}$-activated $\mathrm{K}^{+}$channels
(SK), and a large-conductance anion channels. This work is a basis for a more detailed study of the channels from mouse L929 line cells.

\section{Conflict of Interest}

There is no conflict of interest.

\section{Acknowledgements}

This study was funded by the Scientific Research Fund of Maria Curie-Skłodowska University and the Medical University of Lublin.

\section{References}

BOSMA MM: Anion channels with multiple conductance levels in a mouse lymphocyte-B cell-line. J Physiol 410: 67-90, 1989.

CHOI S, LEE W, YUN J, SEO J, LIM I: Expression of $\mathrm{Ca}^{2+}$-activated $\mathrm{K}^{+}$channels and their role in proliferation of rat cardiac fibroblasts. Korean J Physiol Pharmacol 12: 51-58, 2008.

COULOMBE A, CORABOEUF E: Large-conductance chloride channels of newborn rat cardiac myocytes are activated by hypotonic media. Pflug Arch Eur J Phy 422: 143-150, 1992.

DIXON DM, VALKANOV M, MARTIN RJ: A patch-clamp study of the ionic selectivity of the large conductance, Ca-activated chloride channel in muscle vesicles prepared from Ascaris suum. J Mebrane Biol 131: 143-149, 1993.

DOROSHENKO P: High intracellular chloride delays the activation of the volume-sensitive chloride conductance in mouse L-fibroblasts. J Physiol 514: 437-446, 1999.

ESTACION M: Characterization of ion channels seen in subconfluent human dermal fibroblasts. $J$ Physiol 436: 579-601, 1991.

ETCHEBERRIGARAY R, ITO E, OKA K, TOFELGREHL B, GIBSON GE, ALKON DL: Potassium channel dysfunction in fibroblasts identifies patients with Alzheimer disease. Proc Natl Acad Sci U S A 90: 8209-8213, 1993.

FISKE JL, FOMIN VP, BROWN ML, DUNCAN RL, SIKES RA: Voltage-sensitive ion channels and cancer. Cancer Metast Rev 25: 493-500, 2006.

FRACE AM, GARGUS JJ: Activation of single-channel currents in mouse fibroblasts by platelet-derived growth factor. Proc Natl Acad Sci U S A 86: 2511-2515, 1989.

GALIETTA LJV, MASTROCOLA T, NOBILE M: A class of non-selective cation channels in human fibroblasts. FEBS Lett 253: 43-46, 1989.

GOODWIN PA, CAMPBELL KE, EVANS BAJ, WANN KT: In vitro patch-clamp studies in skin fibroblasts. J Pharmacol Toxicol 39: 229-233, 1998.

HANCOCK JM, WEATHERALL KL, CHOISY SC, JAMES AF, HANCOX JC, MARRION NV: Selective activation of heteromeric SK channels contributes to action potential repolarization in mouse atrial myocytes. Heart Rhythm 12: 1003-1015, 2015.

HIRSCHBERG B, MAYLIE J, ADELMAN JP, MARRION NV: Gating properties of single SK channels in hippocampal CA1 pyramidal neurons. Biophys J 77: 1905-1913, 1999.

HOSOI S, SLAYMAN CL: Membrane voltage, resistance, and channel switching in isolated mouse fibroblasts (L-cells) - a patch-electrode analysis. J Physiol 367: 267-290, 1985.

JALONEN T: Single-channel characteristics of the large-conductance anion channel in rat cortical astrocytes in primary culture. Glia 9: 227-237, 1993.

KOHLER M, HIRSCHBERG B, BOND CT, KINZIE JM, MARRION NV, MAYLIE J, ADELMAN JP: Smallconductance, calcium-activated potassium channels from mammalian brain. Science 273: 1709-1714, 1996. 
MITCHELL CH, WANG L, JACOB TJC: A large-conductance chloride channel in pigmented ciliary epithelial cells activated by GTP $\gamma$ S. J Membrane Biol 158: 167-175, 1997.

NOBILE M, GALIETTA LJV: A large conductance $\mathrm{Cl}^{-}$channel revealed by patch-recordings in human fibroblasts. Biochem Biophys Res Commun 154: 719-726, 1988.

PAHAPILL PA, SCHLICHTER LC: $\mathrm{Cl}^{-}$channels in intact human T lymphocytes. J Membrane Biol 125: 171-183, 1992.

PERES A, STURANI E, ZIPPEL R: Properties of the voltage-dependent calcium-channel of mouse Swiss 3T3 fibroblasts. $J$ Physiol 401: 639-655, 1988a.

PERES A, ZIPPEL R, STURANI E, MOSTACCIUOLO G: A voltage-dependent calcium current in mouse Swiss 3T3 fibroblasts. Pflug Arch Eur J Phy 411: 554-557, 1988 b.

PEREZ-REYES E: Molecular physiology of low-voltage-activated T-type calcium channels. Physiol Rev 83: 117-161, 2003.

REPP H, KOSCHINSKI A, DECKER K, DREYER F: Activation of a $\mathrm{Ca}^{2+}$-dependent $\mathrm{K}^{+}$current in mouse fibroblasts by lysophosphatidic acid requires a pertussis toxin-sensitive G protein and Ras. Naunyn Schmiedebergs Arch Pharmacol 358: 509-517, 1998.

SOH H, PARK CS: Localization of divalent cation-binding site in the pore of a small conductance $\mathrm{Ca}^{2+}$-activated $\mathrm{K}^{+}$channel and its role in determining current-voltage relationship. Biophys $J$ 83: 2528-2538, 2002.

STUMPFF F, MARTENS H, BILK S, ASCHENBACH JR, GAEBEL G: Cultured ruminal epithelial cells express a large-conductance channel permeable to chloride, bicarbonate, and acetate. Pflug Arch Eur J Phy 457: 1003-1022, 2009.

SUN XP, SUPPLISSON S, TORRES R, SACHS G, MAYER E: Characterization of large-conductance chloride channels in rabbit colonic smooth-muscle. J Physiol 448: 355-382, 1992.

THEERAKITTAYAKORN K, BUNPRASERT T: Differentiation capacity of mouse L929 fibroblastic cell line compare with human dermal fibroblast. World Acad Sci Eng Technol 50: 373-376, 2011.

THOMPSON RJ, NORDEEN MH, HOWELL KE, CALDWELL JH: A large-conductance anion channel of the Golgi complex. Biophys J 83: 278-289, 2002.

THORNELOE KS, KNORN AM, DOETSCH PE, LASHINGER ESR, LIU AX, BOND CT, ADELMAN JP, NELSON MT: Small-conductance, $\mathrm{Ca}^{2+}$-activated $\mathrm{K}^{+}$channel 2 is the key functional component of SK channels in mouse urinary bladder. Am J Physiol Regul Integr Comp Physiol 294: R1737-R1743, 2008.

THOROED SM, BRYAN-SISNEROS A, DOROSHENKO P: Protein phosphotyrosine phosphatase inhibitors suppress regulatory volume decrease and the volume-sensitive $\mathrm{Cl}^{-}$conductance in mouse fibroblasts. Pflug Arch Eur J Phy 438: 133-140, 1999.

TUTEJA D, XU DY, TIMOFEYEV V, LU L, SHARMA D, ZHANG Z, XU YF, NIE LP, VAZQUEZ AE, YOUNG JN, GLATTER KA, CHIAMVIMONVAT N: Differential expression of small-conductance $\mathrm{Ca}^{2+}$-activated $\mathrm{K}^{+}$ channels SK1, SK2, and SK3 in mouse atrial and ventricular myocytes. Am J Physiol Heart Circ Physiol 289: H2714-H2723, 2005.

XIA XM, FAKLER B, RIVARD A, WAYMAN G, JOHNSON-PAIS T, KEEN JE, ISHII T, HIRSCHBERG B, BOND CT, LUTSENKO S, MAYLIE J, ADELMAN JP: Mechanism of calcium gating in small-conductance calciumactivated potassium channels. Nature 395: 503-507, 1998. 